\title{
THE IMPAIRMENT OF SPATIAL MEMORY FOLLOWING LOW-LEVEL SARIN INHALATION EXPOSURE AND ANTIDOTAL TREATMENT IN RATS
}

\begin{abstract}
Jiří Kassa, Gabriela Krejčová, Josef Vachek
Purkyně Military Medical Academy in Hradec Králové: Department of Toxicology

Summary: 1. To study the influence of antidotes on low-level sarin-induced impairment of cognitive functions, the rats were exposed to three various low concentrations of sarin (LEVEL 1-3) for 60 minutes in the inhalation chamber. In addition, one group of rats was exposed to LEVEL 2 of sarin repeatedly. 2. Testing of cognitive functions was carried out using the Y-maze evaluating learning and spatial memory. The correct averse behavior of sarin-exposed rats in the Y-maze was tested several times within four weeks following sarin inhalation exposure and antidotal treatment to look for any cognitive impairments. 3. The results were compared to the Y-maze performance of sarin-exposed rats without antidotal treatment and control rats exposed to pure air instead of sarin with or without antidotal treatment. While antidotal treatment was able to eliminate a short-term deficiency in the Y-maze performance in rats exposed to the LEVEL 1 of sarin, a significant decrease in the Y-maze performance in rats exposed to sarin at the LEVEL 2 and 3 was only shortened. Sarin-induced spatial memory impairments in rats exposed repeatedly to sarin at the LEVEL 2 was also shortened when rats were treated following each sarin inhalation exposure. 4 . The findings confirm that antidotes currently used for nerve agent poisonings are beneficial for the treatment of rats singly or repeatedly exposed to non-convulsive symptomatic or even clinically asymptomatic concentrations of sarin.
\end{abstract}

Key words: Sarin; Low-level inhalation exposure; Spatial memory; Rat; Antidotal treatment

\section{Introduction}

The potential for the exposure to highly toxic organophosphorus compounds (OPs), called nerve agents, exists on the battlefield (e.g. Iran-Iraq war) as well as in a civilian sector as a threat by a terrorist group (e.g. Tokyo subway incident - 16) or as an accident as part of current demilitarization efforts. The irreversible binding to and subsequent inactivation of acetylcholinesterase (AChE, EC 3.1.1.7) in the central as well as peripheral nervous system allowing accumulation of acetycholine (ACh) and excessive stimulation of postsynaptic cholinergic receptors is generally believed to be the major mechanism of poisoning. The overstimulation of central cholinergic system is followed by the activation of other neurotransmitter systems including glutamate receptors leading to the increase in extracellular levels of the excitatory amino acid glutamate, a major excitotoxin mediating central neurotoxicity of OPs $(14,24)$. Signs of acute toxicity with extensive AChE inhibition also include autonomic dysfunction (e.g. excessive salivation, lacrimation, urination and defecation), involuntary movements (e.g. tremor, fasciculation) and respiratory dysfunction $(12,26)$. Acute exposure to nerve agents also produces psychiatric symptomatology that includes depression, anti- social thoughts, irrationality, emotional lability and anxiety (23).

OP-induced cholinergic effects are usually manifested immediately following high-level exposure $(12,26)$, nevertheless, there are numerous studies in both humans and animals showing that survivors of high-level OP exposure can experience subtle but significant long-term neurological and neuropsychological outcomes that are detectable months or even years following the recovery from acute poisoning (3). In addition, behavioral alterations and impairments of cognitive functions were found following acute exposure to OPs in the absence of any classic signs of cholinergic toxicity $(10,21)$.

The current standard antidotal treatment for poisoning with OPs usually consists of combined administration of anticholinergic drugs (preferably atropine) and oximes (preferably pralidoxime, obidoxime and HI-6). Anticholinergic drugs block effects of overstimulation by accumulated ACh at muscarinic receptors sites while oximes repair biochemical lesions by dephosphorylating the enzyme molecule and restoring activity $(7,12)$. Nevertheless, very little is known about possible beneficial effects of antidotal treatment in the case of exposure to low-level, clinically asymptomatic concentrations of OPs. The purpose of 
this study is to find out whether standard antidotal treatment of poisonings with OPs is able to influence low-level sarin-induced long-term adverse effects on cognitive functions, especially spatial memory, in rats.

\section{Methods}

Male albino Wistar rats weighing 170-190 g were purchased from VÚFB Konárovice. They kept in an air-conditioned room with light from $07: 00$ to $19: 00 \mathrm{~h}$ at room temperature in cages $(370 \times 570 \times 200 \mathrm{~mm}, 10$ animals/cage $)$ and allowed to access to standard food and tap water ad libitum. The rats were divided in eight groups of ten experimental animals per group (four group were treated with antidotes following sarin inhalation exposure, other four groups were treated with saline instead of antidotes following sarin inhalation exposure) and two control groups $(\mathrm{N}=$ 10) exposed to pure air instead of sarin with or without antidotal treatment. Handling of the experimental animals was done under supervision of the Ethics Committee of the Medical Faculty of Charles University and Purkyně Military Medical Academy.

Sarin was obtained from Zemianské Kostolany (Slovak Republic) and was $98.5 \%$ pure. The oxime HI-6 of $98 \%$ purity was synthesized at the Department of Toxicology of the Military Medical Academy, Hradec Králové. The purity was analysed using a HPLC technique. All other chemicals of analytical grade were obtained commercially and used without further purification.

The experimental rats were exposed to various low concentrations of sarin for 60 minutes in the inhalation chamber while control rats were exposed to pure air for 60 minutes in the same inhalation chamber. The chamber is a box $(300 \times 400 \times 250 \mathrm{~mm})$ made from enamel metal with sarin applicator where the rats are placed in the cage ( $185 \times 310 \times 65 \mathrm{~mm}, 3$ rats/cage). Three concentration of sarin were chosen:

- clinically and laboratory asymptomatic concentration $(0.8 \mu \mathrm{g} / \mathrm{L})$ with a non-significant inhibition of erythrocyte AChE by $10 \%$ - LEVEL 1

- clinically asymptomatic concentration with a significant inhibition of erythrocyte AChE by $30 \%(1.25 \mu \mathrm{g} / \mathrm{L})$ - LEVEL 2. This concentration was used for a single (LEVEL 2) or repeated (three times, each other day) exposure (LEVEL 2R). After the third exposure, a significant inhibition of erythrocyte AChE by $48 \%$ was measured.

- non-convulsive symptomatic concentration with a significant inhibition of erythocyte AChE by $50 \%(2.5 \mu \mathrm{g} / \mathrm{L})$ - LEVEL 3

The erythocyte AChE activity of sarin-exposed rats was measured in another experiment immediately following the inhalation exposure by the same laboratory using Ellman spectrophotometric method (9). The development of sarininduced $\mathrm{AChE}$ inhibition during the testing of cognitive functions was not followed. In the case of 60 minute inha- lation exposure in the same experimental conditions, the lethal concentration of sarin for rats was $4.48 \mu \mathrm{g} / \mathrm{L}$ and the convulsive concentration of sarin for rats was $3.25 \mu \mathrm{g} / \mathrm{L}$.

One minute following the end of inhalation exposure, four groups of experimental rats and one group of control rats were treated intramuscularly (i.m.) with atropine and the oxime HI-6 at human relevant doses corresponding to $2 \%$ of their $\mathrm{LD}_{50}$ value. In the case of repeated sarin exposure, the rats were treated with atropine and HI-6 following each sarin inhalation exposure. Other four group of experimental rats and one group of control rats were treated with saline instead of antidotes.

Cognitive functioning was tested using a Y-maze with averse motivation by a strong electric footshock, evaluating learning and spatial memory (11). The Y-maze is a fully automated apparatus used for the study of behavior of laboratory rats. It is a plastic box consisting of a square start area (285x480 $\mathrm{mm})$ separated by a plexiglass sliding door from two trapezoid, black and white arms - choice area (140x324 $\mathrm{mm}$ ). The grid-floor in the start and choice area is electrifiable. The animals are placed on the start area and after a couple of seconds, electric footshocks $(60 \mathrm{~V}, 50 \mathrm{~Hz}$, duration $0.5 \mathrm{~s}$ ) are applicated at 5 second intervals. The rats try to avoid the shock by escaping to one of two arms. In the case of moving of a rat to wrong (dark) arm, the rats fail to avoid further footshock. The animals were taught spatial discrimination with the preference of black or white arm in the Y-maze. The latency to enter the correct arm was measured and the number of wrong entries was counted. Before inhalation exposure to sarin, the rats were trained to avoid footshock by moving to correct (white) arm in the Y-maze. It usually tooks 4 weeks of training to reach the criterion which was $80 \%$ or more correct averse behavior (moving to the correct arm) within less than 1.5 second. During the training, 10 sessions (two trials/session) per week lasting 4 minutes were realized. The exposure started the day after the animals had reached this criterion. The spatial memory was tested 1 hour, 2 hours, 1 day and 1 week following the sarin inhalation exposure and then, once a week till the end of the fifth week following the exposure. The latency time to enter the correct arm by sarin-exposed treated rats and the number of entry errors were compared to the values obtained from sarin-exposed non-treated rats and the control rats exposed to the pure air instead of sarin.

Analysis of variance (ANOVA) with Bonfferoni's corrections for multiple comparisons was used for the determination of significant differences between experimental and control values (1). The differences were considered significant when $\mathrm{P}<0.05$.

\section{Results}

The results of the influence of various sarin concentrations on the Y-maze performance of rats following the single inhalation exposure and the influence of antidotal treatment with atropine and the oxime HI-6 on low level sa- 
rin-induced impairment of spatial memory are shown in Figure 1-3. While treated as well as non-treated control rats did not show any changes in the rapidity of spatial discrimination in Y-maze following their exposure to the pure air in comparison with the values obtained before the exposure, a spatial memory of rats exposed to LEVEL 1 of sarin was significantly influenced for a short time $(\mathrm{P}<0.05)$. On the other hand, experimental rats exposed to LEVEL 1 of sarin, treated with atropine and the oxime HI-6, did not show any significant increase in the reaction time following the exposure and antidotal treatment (Fig. 1).

The significant increase in the reaction time of rats exposed to LEVEL 2 of sarin was also demonstrated for a short time $(P<0.05)$. The antidotal treatment was only able to shorten, not eliminate a significant decrease in Y-maze performance of rats exposed to LEVEL 2 of sarin (Fig. 2).

The rats exposed to LEVEL 3 of sarin showed a significant decrease in Y-maze performance for a relatively long

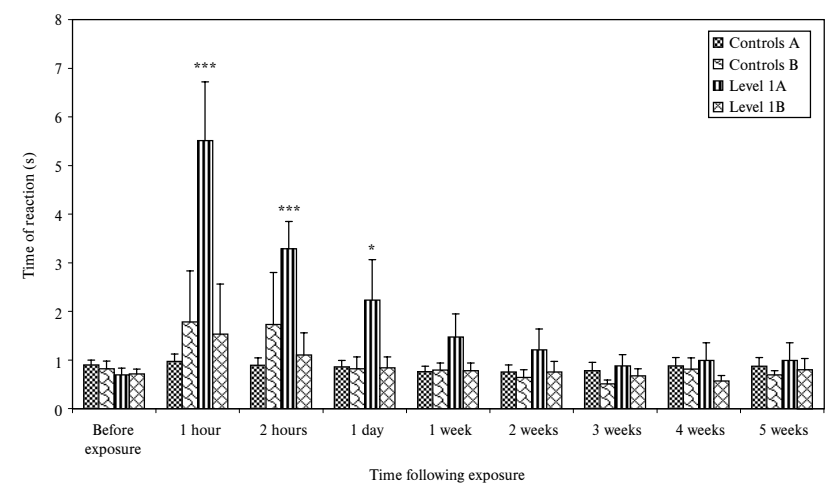

Fig. 1: The alteration of the Y-maze performance in rats singly exposed to LEVEL 1 of sarin and treated with atropine and the oxime HI-6, where A - without antidotal treatment, B - with antidotal treatment. Statistical significance: $* \mathrm{P}<0.05, * * \mathrm{P}<0.01, * * * \mathrm{P}<0.001$.

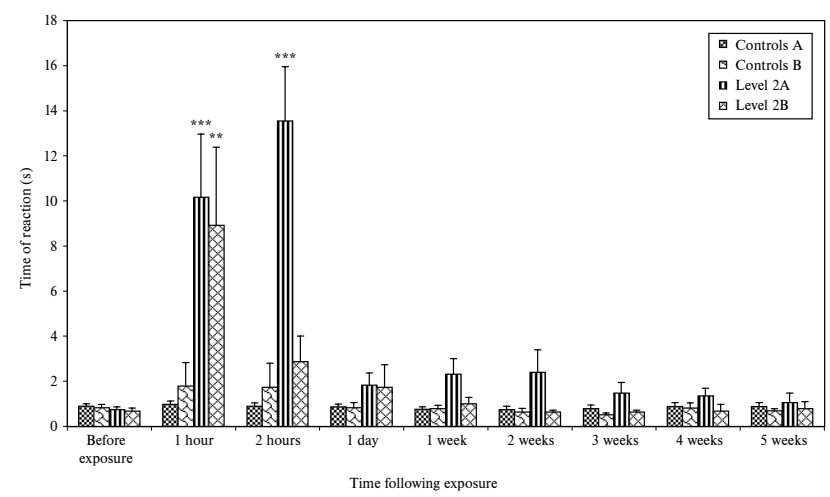

Fig. 2: The alteration of the Y-maze performance in rats singly exposed to LEVEL 2 of sarin and treated with atropine and the oxime HI-6. Symbols and statistical significance - see Fig. 1. time (until the third week following the exposure) ( $\mathrm{P}<$ $0.05)$. When the experimental rats were treated with atropine and the oxime HI-6, the sarin-induced impairments of spatial memory was markedly shortened (until the second hour following the exposure and treatment) (Fig. 3). In contrast to the reaction time, the number of entry errors of experimental rats was not different from the number of entry errors of control rats exposed to pure air, regardless of the sarin concentration used for the inhalation exposure of experimental rats.

The results of Y-maze performance of rats repeatedly exposed to LEVEL 2 of sarin compared to control values are given in Figure 4. While the first exposure to LEVEL 2 brought only short-time increase in the reaction time of sarin-exposed rats, the second and the third exposure to the same sarin concentration caused a significantly higher and longer spatial memory impairments compared to rats singly exposed to LEVEL 2 of sarin. The decrease in Y-maze performance of repeatedly exposed rats lasted until the end of

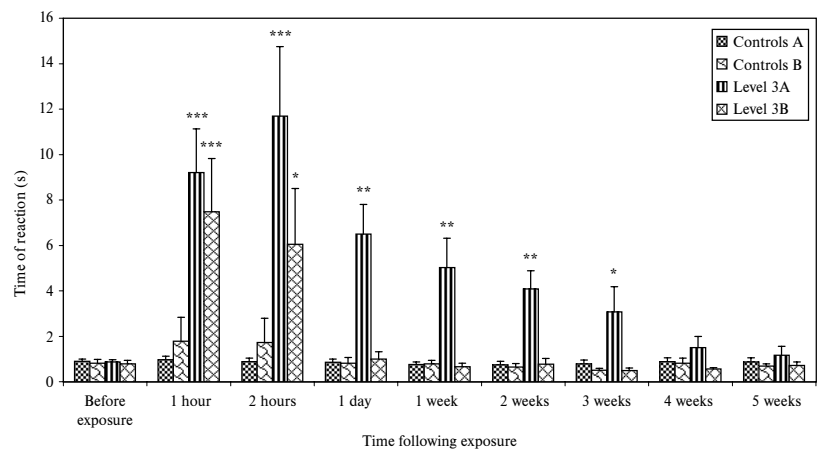

Fig. 3: The alteration of the Y-maze performance in rats singly exposed to LEVEL 3 of sarin and treated with atropine and the oxime HI-6. Symbols and statistical significance - see Fig. 1.

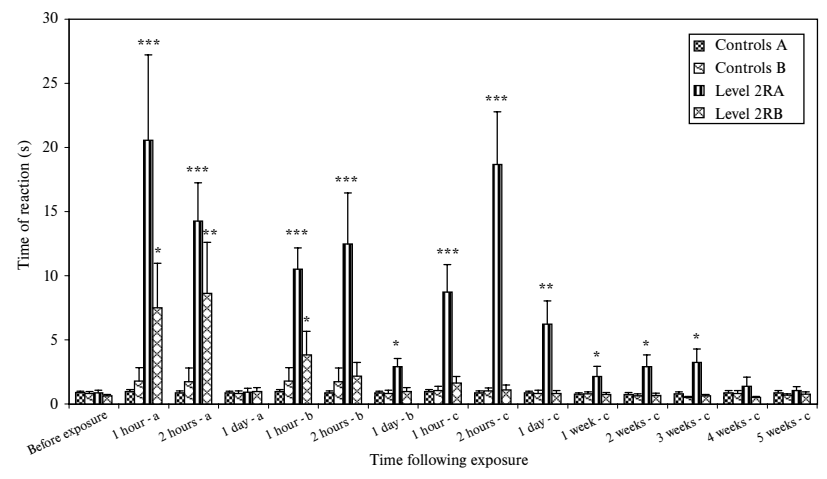

Fig. 4: The alteration of the Y-maze performance in rats repeatedly exposed ( $\mathrm{a}$ - the first exposure, $\mathrm{b}$ - the second exposure, $\mathrm{c}$ - the third exposure) to LEVEL 2 of sarin and treated with atropine and the oxime HI-6. Symbols and statistical significance - see Fig. 1. 
the third week following the last exposure to sarin. When sarin-exposed rats were treated with antidotes following each sarin exposure, the first and second exposure to LEVEL 2 only brought short-term increase in the reaction time of sarin-exposed rats $(\mathrm{P}<0.05)$ and the third exposure to the same sarin concentration did not cause any spatial memory impairment (Fig. 4). The number of entry errors of rats repeatedly exposed to LEVEL 2 of sarin did not differ from control values.

\section{Discussion}

Acetylcholine is important in the modulation of various brain functions, including learning and memory, attention, arousal and the control of locomotor activity $(2,8)$. Therefore, a shift in the cholinergic activity produced by OPs leads to functional changes in humans and animals, which may be observed as cognitive dysfunction $(6,25)$. Impairment of cognitive functions, especially incapacitation of learning and memory, belongs to the most frequent central signs of acute OP poisoning (12,13). In addition, the adverse effects of OP compounds on cognition functions, such as learning and memory, may persist for quite some time after termination of toxicant exposure. The results from several studies have demonstrated the presence of OP-induced learning impairments several days after the behavioral signs of OP toxicity have subsided $(4,5,13)$. The chronic exposure to OP agents can also result in specific long-term cognitive deficits even when signs and symptoms of excessive cholinergic activity are not present $(18,19)$. Epidemiological studies showed alterations in cognitive functions, impaired memory and concentrations in humans after chronic low-dosage occupational exposure to organophosphorus insecticides $(17,25)$. In addition, a behavioral alteration indicative of an increase in anxiety and impairment of cognitive functions, especially spatial memory, in the absence of any classic signs of overstimulation of cholinergic nervous system has been demonstrated after acute low-dosage exposure of experimental animals to OPs $(10,21)$. Thus, the significant, clinically manifested AChE inhibition in the central nervous system leading to the neuronal degeneration of some brain regions including hippocampus, associated with the spatial learning and memory, is not necessary for the clinically manifested cognitive impairments. These findings correspond with earlier published data about neurological and neurophysiological outcomes detectable months or even years following recovery from acute OP poisoning (22, 28).

Our data clearly demonstrate that low-level sarin-induced decrease in Y-maze performance of rats is significantly influenced by the administration of standard antidotal treatment consisting of atropine and the oxime HI-6 shortly following sarin inhalation exposure. The administration of antidotes significantly shortened low-level sarin-induced impairment of spatial memory but they were not able to eliminate the increase in the reaction time in
Y-maze. While non-treated rats singly exposed to sarin at LEVEL 3 or repeatedly exposed to sarin et LEVEL 2 showed long-term impairment of spatial memory lasting till the end of the third week following the inhalation exposure, rats treated with atropine and HI-6 suffered from sarin-induced impairment of cognitive functions very shortly (till 2 hours following the exposure) regardless of the concentration of sarin or number of sarin exposures.

It is rather difficult to explain the therapeutic effects of standard antidotes if they are administered following the exposure to OPs at levels that do not cause clinical signs of overstimulation of postsynaptic cholinergic receptors because their efficacy consists in blocking the effect of accumulated $\mathrm{ACh}$ at muscarinic receptor sites (atropine) and reactivating OP-inhibited AChE (HI-6). However, the ability of tested antidotes to shorten long-lasting impairments of spatial memory induced by low-level sarin inhalation exposure may be due to other antidotal mechanisms based on direct antimuscarinic and ganglion blocking actions, restoration of cholinergic transmission, retardation of the formation of the aged inhibitor-enzyme complex and inhibition of ACh release (20,27).

Although our findings are difficult to extrapolate directly to human low level exposure to OPs, they indicate that antidotes currently used for nerve agent poisonings seem to be beneficial for the antidotal treatment of humans exposed to low-dosage of OPs because they are able to shorten OP-induced chronic decline of memory functions observed, for example, in first responders exposed to sarin in the Tokyo subway attack (15). Therefore, the antidotal treatment of OP-exposed humans seems to be rational regardless of the dosage of OPs.

\section{Acknowledgement}

The authors thank to Mrs. E. Reslová and Mrs. E. Vodáková for their skilful technical assistance and to Mgr. V. Bláha for the statistical evaluation. This study was supported by the grant of Ministry of Defence, No. 03021100006.

\section{References}

1. Afifi AA, Azen SP. Statistical analysis and computer oriented approach. $2^{\text {nd }}$ ed. New York: Academic Press, 1979:p.442.

2. Brito GN, Davis BJ, Stoop LC, Stanton ME. Memory and the septo-hippocampal cholinergic system in the rat. Psychopharmacology 1983; 81:315-20.

3. Brown MA, Kelley AB. Review of health consequences from high-, intermediate- and low-level exposure to organophosphorus nerve agents. J Appl Toxicol 1998;18:393-408.

4. Buccafusco JJ, Heithold DL, Chon SH. Long-term behavioral and learning abnormalities produced by the irreversible cholinesterase inhibitor soman: effect of a standard pretreatment regimen and clonidine.Toxicol Lett 1990;52:319-29.

5. Bushnell PJ, Padilla SS, Ward T, Pope CN, Olszyk VB. Behavioral and neurochemical changes in rats dosed repeatedly with diisopropylfluorophosphate. J Pharmacol Exp Ther 1991;256:741-50.

6. Bushnell PJ, Kelly KL, Ward TR. Repeat inhibition of cholinesterase by chlorpyrifos in rats: behavioral, neurochemical and pharmacological indices of tolerance. J Pharmacol Exp Ther 1994;270:15-25.

7. Dawson RM. Review of oximes available for treatment of nerve agent poisoning. J Appl Toxicol 1994;17:317-31.

8. Day J, Seidler FJ, Slotkin TA. Cholinergic activity in the rat hippocampus, cortex and striatum correlates with locomotor activity. An in vivo microdialysis study. Pharmacol Biochem. Behav 1990;38:723-9. 
9. Ellman GL, Courtney DK, Andres V, Featherstone RM. A new and rapid colorimetric determination of acetylcholinesterase activity. Biochem Pharmacol 1961; 7:88-95.

10. Kassa J, Koupilová M, Vachek J. The influence of low-level sarin inhalation exposure on spatial memory in rats. Pharmacol Biochem Behav 2001;70:175-9.

11. Koupilová M, Patočka J, Herink J. Effects of dalargin and methyl-D-Phe4-dalargin upon spatial orientation of rats. Homeostasis 1995:36:239-40.

12. Marrs TC. Organophosphate poisoning. Pharmacol Ther 1993;58:51-66

13. McDonald BE, Costa LG, Murphy SD. Spatial memory impairment and centra muscarinic receptor loss following prolonged treatment with organophosphates. Toxicol Lett 1988;40:47-56.

14. McDonough JH, Shih TM. Neuropharmacological mechanisms of nerve agentinduced seizure and neuropathology. Neurosci Biobehav Rev 1997;21:559-79.

15. Nishiwaki Y, Maekawa K, Ogawa Y, Asukai N, Minami M, Omae K. Effects of sarin on the nervous system in rescue team staff members and police officers 3 years after the Tokyo subway sarin attack. Environ Health Perspect 2001:109(11): 1169-73.

16. Ohtomi S, Takase M, Kunagoi F. Sarin poisoning in Japan. A clinical experience in Japan Self Defense Force (JSDF) Central Hospital. Int Rev Arm For Med Ser 1996;69:97-102.

17. Parrón T, Hernández AF, Pla A, Villanueva E. Clinical and biochemical changes in greenhouse sprayers chronically exposed to pesticides. Hum Exp Toxico 1996;5:957-63.

18. Prendergast MA, Terry AV, Buccafusco JJ. Chronic, low-level exposure to diisopropylfluorophosphate causes protracted impairment of spatial navigation learning. Psychopharmacology 1997;130:276-84.

19. Prendergast MA, Terry AV, Buccafusco JJ. Effects of chronic, low-level organophosphate exposure on delayed recall, discrimination and spatial learning in monkeys and rats. Neurotoxicol Teratol 1998;20:115-22.

20. Rousseaux CG, Dua AK. Pharmacology of HI-6, an H series oxime. Can J Physiol Pharmacol 1989;67:1183-9.

21. Sánchez-Amate MC, Flores P, Sánchez-Santed F. Effects of chlorpyrifos in the plus-maze model of anxiety. Behav Pharmacol 2001;12:285-92.
22. Savage EP, Keefe TJ, Mounce LM, Heaton RK, Lewis JA, Burcar PJ. Chronic neurological sequelae of acute organophosphate pesticide poisoning. Arch Environ Health 1988;43:38-45.

23. Sidell FR. Soman and sarin: clinical manifestation and treatment of accidental poisoning by organophosphates. Clin Toxicol 1974;7:1-17.

24. Solberg Y, Belkin M. The role of excitotoxicity in organophosphorus nerve agent central poisoning. TiPS 1997;18:183-5.

25. Stephens R, Spurgeon A, Calvert IA. Neuropsychological effects of long-term exposure to organophosphates in sheep dip. Lancet 1995;345:1135-9.

26. Taylor P. Anticholinesterase agents. In: Hardman JG, Limbird LE, editors. The Pharmacological basis of therapeutics, $9^{\text {th }}$ ed. New York: McGraw Hill, 1996: p.161-76.

27. van Helden HPM, Busker RW, Melchers BPC, Bruijnzeel PLB. Pharmacological effects of oximes: how relevant are they? Arch Toxicol 1996;70:779-86.

28. Yokoyama K, Araki S, Murata K, Nishikitami M, Okumura T, Ishimatsu S, Takasu A. Chronic neurobehavioral and central and autonomic nervous system effects in Tokyo subway sarin poisoning. J. Physiol (Paris) 1998;92:317-23.

Submitted August 2002.

Accepted September 2002.

Doc. MUDr. Jiří Kassa, CSc., P.O. Box 35/T, Purkyně Military Medical Academy, 50001 Hradec Králové, Czech Republic. e-mail: kassa@pmfhk.cz 